\title{
Primary Digestive Richter's Syndrome
}

Marie Parrens, M.D., Bassem Sawan, M.D., Pierre Dubus, M.D., Ph.D., Francis Lacombe, M.D., Ph.D., Gérald Marit, M.D., Ph.D., Béatrice Vergier, M.D., Ph.D., Josy Reiffers, M.D, Ph.D.,

Antoine de Mascarel, M.D., Ph.D., Jean Philippe Merlio, M.D., Ph.D.

Departments of Pathology and Molecular Biology (MP, BS, PD, BV, AdM, J-PM) and Hematology

(GM, FL, JR), Hôpital du Haut-Lévêque, Pessac, France

The clinical and morphologic transformation of 3 to $5 \%$ of chronic lymphocytic leukemia (CLL) to diffuse large-cell lymphoma (DLCL) is commonly referred to as Richter's syndrome. Richter's syndrome occurs mostly in lymph nodes and may represent a second neoplasm or a transformation from the same clonal population. Clinical features in six patients with digestive Richter's syndrome were recorded. Paired samples of CLL and DLCL were investigated by immunohistological analysis $(n=6)$ and by polymerase chain reaction (PCR) for immunoglobulin heavy-chain gene rearrangement $(n=$ 4). Histological examination revealed the involvement of the gastrointestinal tract by DLCL of B-cell phenotype $(n=6)$. The same monoclonal rearrangement between CLL and DLCL was demonstrated by PCR and sequencing analyses in two patients. The monoclonal rearrangement was different between CLL and DLCL in only one case. Median survival was 22 months for five patients receiving chemotherapy, suggesting that digestive Richter's syndrome has a better prognosis than nodal Richter's syndrome. Indeed, appropriate surgical resection combined with chemotherapy led to partial or complete remission in four patients.

KEY WORDS: CLL, Digestive Richter's syndrome, Gene rearrangement. Mod Pathol 2001;14(5):452-457

Approximately 3 to $5 \%$ of cases of chronic lymphocytic leukemia (CLL) show evidence of morphologic transformation into diffuse large-cell lymphoma (DLCL; 1, 2) or Hodgkin's disease (3-8). This pro-

Copyright ( $(2001$ by The United States and Canadian Academy of Pathology, Inc.

VOL. 14, NO. 5, P. 452, 2001 Printed in the U.S.A.

Date of acceptance: December 19, 2000.

This work was supported by a grant from the Ligue Contre le Cancer, Comité des Pyrénées Atlantiques.

Authors Parrens and Sawan contributed equally to this work.

Address reprint requests to: Marie Parrens, M.D., EA 2406, Department of Pathology and Molecular Biology, CHU et Université de Bordeaux 2, Hôpital du Haut-Lévêque, 33604 Pessac, France; e-mail: marie. parrens@chu-bordeaux.fr; fax: 05-56-55-64-53. cess is commonly referred to as Richter's syndrome (RS; 9, 10). RS is characterized by rapid lymph node enlargement, splenomegaly, hepatomegaly, fever, and weight loss and is associated with a rapid fatal outcome $(1,2,9,11,12)$. Because patients with CLL have a greater tendency to develop secondary tumors, there has been a debate about the origin of the DLCL. Characterization of immunoglobulin heavy-chain $(\mathrm{IgH})$ gene rearrangement has shown that DLCL may evolve from the original leukemia cell clone $(8,13-21)$ or may be a separate and independent neoplasm $(19,22-26)$. Extranodal involvement, especially of the gastrointestinal tract, is very rare. To our knowledge, only 10 cases have been reported $(10,21,23,27-30)$. Clonal relationship between CLL and digestive RS never has been established by molecular analysis. In one patient, this relationship has been suggested by immunostaining for light and heavy immunoglobulin chains (21). In four other cases, DLCL was not clonally related to the preexisting CLL, suggesting that digestive RS mainly represents a true secondary neoplasm (23). Therefore, we studied the clinicopathology and molecular features of digestive RS in six patients. Our study also suggests that digestive RS may have a better prognosis compared with nodal transformation.

\section{MATERIAL AND METHODS}

\section{Patients}

Six CLL-treated patients developed digestive RS. Samples were fixed in formalin (Cases 1,2, and 5) or in Bouin's liquid (Cases 3, 4, and 6), embedded in paraffin, and stained with hematoxylin and eosin.

In all cases, the initial diagnosis of CLL was established on peripheral blood lymphocytes (PBL) and bone marrow (BM) examination and count. In four cases, lymph nodes $(n=4)$ or spleen $(n=1)$ examined during the CLL phase were reviewed and corresponded to CLL involvement. BM status was also checked at the time of the transformation. 
Immunophenotypic Characterization

Immunohistochemical analysis was performed either on $10 \%$ formalin-fixed paraffin-embedded sections with the biotin-streptavidin-peroxidase LSAB kit on an automated Chemate (DAKO, les Ullis, France) or by flow cytometry (Beckman Coulter XL, Hialeah, FL) of PBL. Primary antibodies were directed against the following antigens: CD3, CD10, CD20, CD23, CD43, Epstein-Barr virus (EBV) latency membrane protein (LMP1), cytokeratin (KL1), Ki67 (MIB1), P53, $\kappa$ and $\lambda$ immunoglobulin light chains (all from DAKO,) and CD5 (Novocastra, Le Perray, France). MIB1 immunostaining was interpreted by a semiquantitative method (31).

\section{Molecular Genetic Studies}

Genomic DNA was extracted from frozen tissues $(n=5)$, formalin-fixed tissues $(n=2)$ and PBL $(n=$ 3 ) according to a standard phenol chloroform procedure. Analysis of IgH gene was performed as previously described (32). The monoclonal-dominant bands of both CLL and DLCL material of Cases 1, 2, and 5 were excised from the gel, eluted, and submitted to nucleotide sequencing analysis using the ABI PRISM Dye Terminator Cycle Sequencing Ready Reaction Kit (Perkin-Elmer Applied Biosystem, Foster City, CA). Nucleotide sequence data were analyzed using the Sequence Navigator Software (Perkin Elmer Applied Biosystem). Sequence comparisons were made with the Genbank-EMBL database using the Wisconsin Package (Genetics Computer Group, Inc, Madison, WI), and the BLAST program (33).

\section{RESULTS}

\section{Clinical Results}

Two males and four females were diagnosed for CLL (average age: $67 \mathrm{y}$ ). Blood cell counts are summarized in Table 1. At initial CLL diagnosis, all patients had blood and BM involvement but no lymphadenopathy. Splenectomy was performed in the single patient (Case 4) who presented splenomegaly and hemolytic anemia. After a variable follow-up period, patients were treated by chlorodeoxyadenosine on the basis of lymphocytosis

TABLE 1. Blood Cell Count at Diagnosis

\begin{tabular}{ccccc}
\hline $\begin{array}{c}\text { Case } \\
\text { Number }\end{array}$ & White Cells & $\begin{array}{c}\text { Lymphocytes } \\
(\%)\end{array}$ & Platelet & $\begin{array}{c}\text { Hemoglobin } \\
\text { (g/dL) }\end{array}$ \\
\hline 1 & 25,000 & 80 & 246,000 & 12.9 \\
2 & 54,100 & 85 & 198,000 & 12.2 \\
3 & 10,000 & 60 & 119,000 & 12.2 \\
4 & 39,560 & 76 & 275,000 & 12 \\
5 & 10,800 & 65 & 263,000 & 13.6 \\
6 & 42,900 & 65 & 160,000 & 12.6 \\
\hline
\end{tabular}

$>50,000$ or tumoral lymphadenopathy or anemia and thrombopenia.

Digestive RS was revealed by recurrent gastric ulcer disease (Cases 1 and 3), upper (Case 4) or lower (Case 5) digestive-tract bleeding, intestinal obstruction (Case 2), or acute perforation (Case 6). At examination, a general alteration was observed, with weight loss and general weakness. The median interval between initial diagnosis of CLL and RS was 82 months (range: 24 to $158 \mathrm{mo}$ ).

\section{Morphologic and}

Immunophenotypic Characterization

The anatomic sites examined for pathologic evaluation are listed in Table 2, and the results of the immunophenotypic study of CLL and DLCL samples are summarized in Table 3. Whatever the anatomic site, CLL corresponded to small monomorphic lymphocytic cells with rare scattered blast cells. Indeed, MIB1 stained only few cells of CLL specimens (Fig. 3A). A typical B-CLL CD5+, CD20+, SIg+, CD23+, CD43+ phenotype was evidenced in all cases (Table 3 ).

Digestive DLCL was diagnosed on the presence of a dense, large lymphoid cell infiltrate of the digestive mucosa (Fig. 1). In five cases (Cases 1, 2, 3, 5 and 6), blastlike large cells had a vesicular nucleus with prominent nucleoli (Fig. 2A). In Case 4, lymphoma cells infiltrating the stomach mucosa had a uniform nucleus with a finely dispersed chromatin and small nucleoli (Fig. 2B). In all DLCL samples, the high mitotic rate was confirmed by the Ki67 (MIB1) staining (Fig. 3B). No lymphoepithelial lesion was found, either at the level of DLCL infiltration or adjacent mucosa, even after cytokeratin staining. The B-cell phenotype of DLCL is shown in Table 3. By comparison with the paired CLL samples, a loss of both CD5 and CD23 expression was found in four DLCL samples (Cases 3, 4, 5, and 6). A decrease in CD5 expression was observed in Case 1

TABLE 2. Clinical Data of Six Patients with RS

\begin{tabular}{ccccll}
\hline $\begin{array}{c}\text { Case } \\
\text { Number }\end{array}$ & Sex & Age (y) $\begin{array}{c}\text { Date of } \\
\text { Diagnosis }\end{array}$ & \multicolumn{1}{c}{ Site $^{\mathrm{a}}$} & Diagnosis \\
\hline 1 & F & 66 & 1994 & LN/BM/PB & CLL \\
& & 69 & 1997 & Stomach & DLCL \\
2 & F & 71 & 1994 & LN/BM/PB & CLL \\
& & 73 & 1996 & Rectum & DLCL \\
3 & F & 60 & 1990 & LN/BM/PB & CLL \\
& & 64 & 1994 & Stomach & DLCL \\
4 & M & 62 & 1983 & Spleen/BM/PB & CLL \\
& & 76 & 1997 & Stomach & DLCL \\
5 & F & 67 & 1988 & PB/BM & CLL \\
& & 78 & 1999 & Intestine & DLCL \\
6 & M & 76 & 1986 & LN/PB/BM & CLL \\
& & 83 & 1994 & Intestine & DLCL \\
\hline
\end{tabular}

LN, lymph node; PB, peripheral blood; BM, bone marrow; M, male; F, female.

a Anatomic sites' involvement based on pathologic evaluation. 
TABLE 3. Immunophenotype of Paired CLL and DLCL Samples in Six Cases of RS

\begin{tabular}{|c|c|c|c|c|c|c|c|c|c|c|c|c|}
\hline \multirow{2}{*}{$\begin{array}{c}\text { Phenotypic } \\
\text { Marker }\end{array}$} & \multicolumn{2}{|c|}{1} & \multicolumn{2}{|c|}{2} & \multicolumn{2}{|c|}{3} & \multicolumn{2}{|c|}{4} & \multicolumn{2}{|c|}{5} & \multicolumn{2}{|c|}{6} \\
\hline & CLL & DLCL & CLL & DLCL & CLL & DLCL & CLL & DLCL & CLL & DLCL & CLL & DLCL \\
\hline CD20 & + & + & + & + & + & + & + & + & + & + & + & + \\
\hline CD5 & + & $+1-$ & + & + & + & - & + & - & + & - & + & - \\
\hline CD3 & - & - & - & - & - & - & - & - & - & - & - & - \\
\hline CD43 & + & + & + & + & + & - & + & + & + & $+1-$ & + & + \\
\hline CD23 & + & + & + & - & + & - & + & - & + & - & + & - \\
\hline$\kappa$ & $\mathrm{NC}$ & NC & + & + & + & + & $\mathrm{NC}$ & $\mathrm{NC}$ & NC & $\mathrm{NC}$ & $\mathrm{NC}$ & + \\
\hline$\lambda$ & $\mathrm{NC}$ & NC & - & - & - & - & $\mathrm{NC}$ & NC & NC & $\mathrm{NC}$ & NC & - \\
\hline P53 & + & + & + & + & - & - & + & +++ & $\mathrm{NC}$ & +++ & - & - \\
\hline Ki67 (MIB1) & $10 \%$ & $80 \%$ & $25 \%$ & $80 \%$ & $5 \%$ & $\mathrm{NC}$ & $5 \%$ & $95 \%$ & $\mathrm{NC}$ & $80 \%$ & $2 \%$ & $60 \%$ \\
\hline
\end{tabular}

NC, noncontributive; +/-, weakly positive.

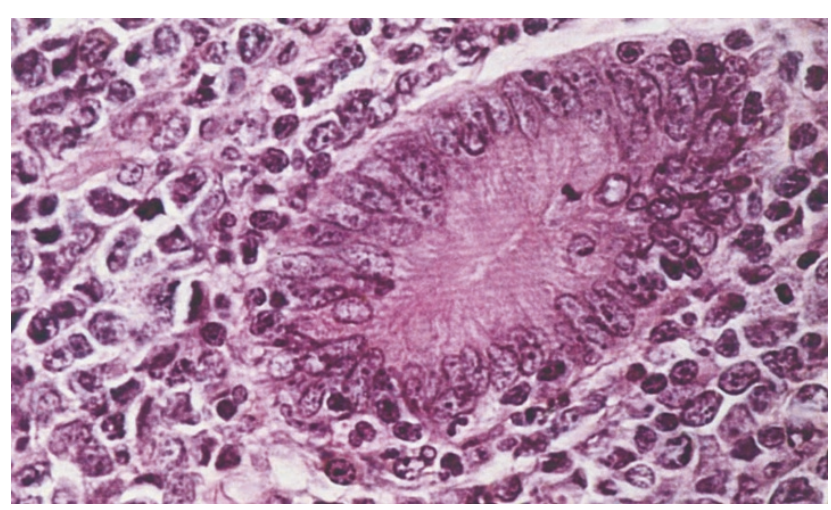

FIGURE 1. Diffuse infiltration of the intestine mucosa by large lymphoma cells (hematoxylin and eosin staining, $\times 400$ ).

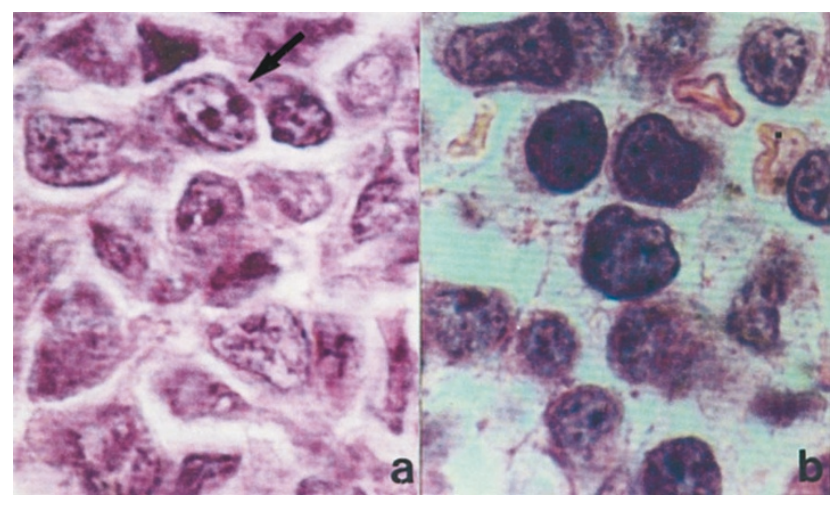

FIGURE 2. (A) Large lymphoma cells with prominent nucleoli (arrow, hematoxylin and eosin staining $[\mathrm{HE}], \times 1000$ ). (B) Large lymphoma cells with clear chromatin and smaller nucleoli in Case 4 $(\mathrm{HE}, \times 1000)$.

and a loss of CD23 expression in Case 2. CD10 expression was negative in all cases except Case 4 . A strong p53 expression was observed in DLCL cells in two cases (Cases 4 and 5). Staining for EBV (LMP1) was negative in all cases. At DLCL diagnosis, bone marrow examination showed only CLL cells in all patients except one with infiltration by the DLCL cells (Case 4).

\section{Molecular Biology}

PCR followed by electrophoresis and nucleotidesequencing analyses demonstrated the same mono-

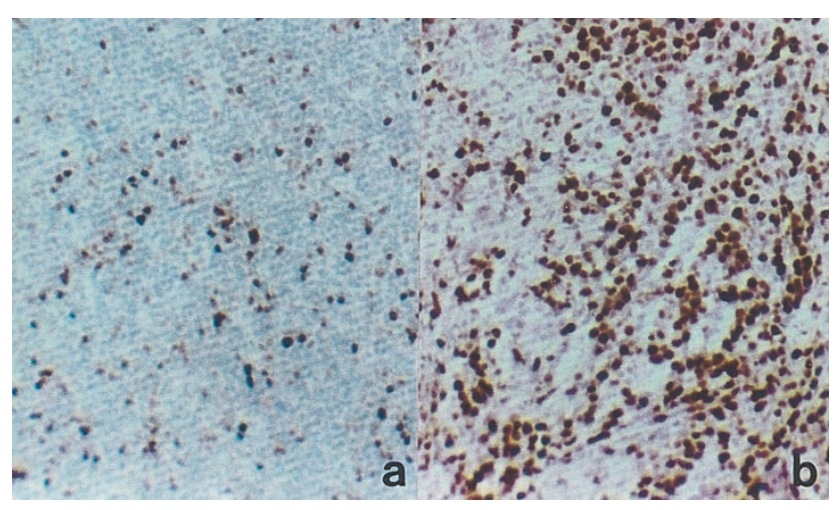

FIGURE 3. MIB1 staining in (A) chronic lymphocytic leukemia (5\% of positive cells) and (B) in diffuse large-cell lymphoma (80\% of positive cells).

clonal IgH rearrangement between CLL and DLCL in two patients (Cases 1 and 2 Fig. 4). In Case 1, a biallelic monoclonal rearrangement was observed at CLL stage, whereas only one monoallelic rearrangement was conserved at DLCL stage. In Case 3, a monoallelic clonal pattern was evidenced in CLL, whereas no monoclonal pattern was found in DLCL, also suggesting allelic loss. In Case 5, two different clonal bands were detected in CLL and DLCL. The CLL band was also barely seen in the DLCL DNA analysis (Fig. 4), suggesting the presence of some residual CLL cells in the RS sample. Sequencing analysis of the dominant bands of CLL and DLCL revealed no homology between the two rearranged junctional regions. Moreover, BLAST and BESTFIT analyses revealed that the JH-joining region of the CLL monoclonal allele was identical to human $\mathrm{JH} 6$ gene, whereas the JH region of the DLCL allele matched to the JH1 gene (34). In two patients (Cases 4 and 6), neither frozen nor formalin-fixed digestive tissue was available for PCR analysis.

\section{Treatment and Survival}

A surgical resection of the tumor was performed in five patients (Cases 1, 2, 3, 5, and 6). One patient died during the postsurgical period (Case 1). Five patients (Cases 2, 3, 4, 5, and 6) were treated by 


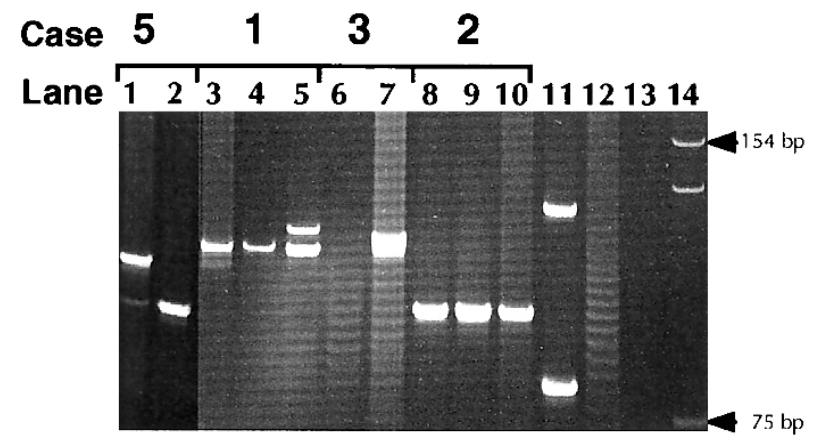

FIGURE 4. Comparison of immunoglobulin heavy-chain gene (IgH) rearrangement in chronic lymphocytic leukemia (CLL) and digestive Richter's syndrome. An identical monoclonal rearrangement was evidenced between CLL and digestive Richter's syndrome (RS) in Case 1 (CLL, Lane 5 and RS, Lanes 3 and 4) and Case 2 (CLL, Lanes 9 and 10 and RS, Lane 8 ). The identity of the IgH rearrangement was confirmed by sequencing analysis. In Case 1, an allele of the initial CLL (Lane 5) is lost in RS (Lanes 3 and 4). For Case 3, a monoclonal rearrangement was found in CLL (Lane 7) but not in RS (Lane 6). In Case 5, a different monoclonal rearrangement was detected in CLL (Lane 2) and in RS (Lane 1). A minor clone, identical to the CLL rearrangement, was also found in RS (Lane 1). Lanes 11 to 13 correspond to monoclonal, polyclonal, and negative controls, respectively.

systemic chemotherapy. One patient received adjuvant radiotherapy (Case 2). After transformation of CLL into RS, the median survival concerning patients treated by chemotherapy was 22 months (range, 5 to $48 \mathrm{mo}$ ). The five patients who died presented with disease. The single living patient (Case 5) presented with lymphocytosis at only 5000 at last examination (see Table 4).

\section{DISCUSSION}

In approximately 3 to $5 \%$ of cases of CLL, the disease progresses to a large-cell lymphoma or Hodgkin's disease $(2,5-7,35)$. Histological progression to large-cell lymphoma also corresponds to a general clinical alteration, as observed in our patients $(1,2,12)$. Transformation occurs in lymph nodes, bone marrow, spleen, or other tissues $(1,2,12)$. The

TABLE 4. Treatment and Response in Patients with Digestive RS

\begin{tabular}{clccc}
\hline Case No. & Regimen & Response & $\begin{array}{c}\text { Duration } \\
(\mathrm{mo})\end{array}$ & $\begin{array}{c}\text { Last } \\
\text { Follow-Up }\end{array}$ \\
\hline 1 & Surgery & NR & 1 & Dead \\
2 & CHVP, XRT & CR & 24 & Dead \\
3 & CVPA & CR & 36 & \\
& Mini-CHOP & PR & 12 & Dead \\
4 & CEOP & NR & 5 & Dead \\
5 & CEOP & CR & 17 & Alive \\
6 & CVP & PR & 16 & Dead \\
\hline
\end{tabular}

mini-CHOP, cyclophosphamide, doxorubicin, vincristine, prednisone; CHVP, cyclophosphamide, doxorubicin, vincristine, prednisone; CEOP, cyclophosphamide, epirubicine, vincristine, prednisone; CVPA, cyclophosphamide, vincristine, prednisone, adriamycine; CVP, cyclophosphamide, vincristine, prednisone; XRT, radiation; CR, complete response; PR, partial response; NR, no response; Dead, dead with disease.

${ }^{\mathrm{a}}$ After relapse. prognosis for RS is very poor, with a median survival of 5 months $(1,2)$. Primary gastrointestinal involvement has been rarely reported $(10,21,23,27-30,36)$. Clinical gastrointestinal manifestations during the CLL phase are rare and should lead to suspect transformation (36). Histologically, the main differential diagnosis remains the DLCL of MALT type, especially at the stomach level. Careful search for low-grade lymphoma component, lymphoepithelial lesions, and immunohistological analysis allowed us to rule out such possibility in our patients. Indeed, DLCL of MALT-type exhibit lymphoepithelial lesions composed of either small or large lymphoid cells $(37,38)$. MALT-type lymphoma cells usually express a CD5-, CD23 - phenotype, whereas DLCL of RS type have an immunophenotype that usually resembles that of the original CLL (CD5+, CD23+, CD43+). However phenotypic changes may be observed (17), as in our patients with digestive RS with a loss of either or both CD5 or CD23. Immunoglobulin light-chain expression between CLL and DLCL may be different even though CLL and DLCL are clonally related $(8,14,20)$. Because of this discordance, immunoglobulin gene rearrangement by Southern blot or PCR is the most appropriate analysis for study of the clonal relationship between CLL and DLCL. Such analysis has provided evidence for the same clonal origin for CCL and DLCL in most patients with nodal RS $(8,13-20)$. In other patients, an independent cellular clone was found at the DLCL phase $(19,22-26)$. When investigated, no clonal relationship between CLL and DLCL was previously established in digestive RS (23). Alternatively, we have demonstrated a common clonal origin at least in two out of four cases tested. In the DLCL of Case 1, only one of the two bands of the CLL was detected, suggesting allelic loss. This was also observed in Case 3. Finally, in only one case (Case 5), a different $\mathrm{IgH}$ gene rearrangement pattern was found between CLL and DLCL. Because IgH gene somatic mutation and/or reiterative rearrangements may in some instances modify the rearranged complementarity-determining Region 3 (17), sequencing analysis showed in this case that the two clonal populations were not related.

Specific oncogene or tumor-suppressor gene alterations involved in the morphologic transformation and clinical progression of CLL to DLCL have not been yet described. p53 has not been involved in the transformation of CLL (19) but may play a role in the development of a second malignancy $(19,39-41)$. Indeed, only two cases were strongly positive in the DLCL phase, whereas weak or negative p53 expression was found in the others. The EBV infection has been implicated in the progression of CLL to Hodgkin-like lymphomas $(4,5,42)$. In our series, EBV immunodetection was negative in all cases of digestive RS. 
Median survival after transformation into RS was 22 months for patients treated by chemotherapy in our series. This differs from the 5 months' term outcome of nodal RS (39 patients; 1). One patient (Case 4) had a poor prognosis (5 months of survival) but was the only one characterized by DLCL bone marrow involvement.

Primary digestive RS seems to be of better prognosis than nodal RS, as previously suggested (21, 36). Indeed, an appropriate surgical resection, followed by chemotherapy led to complete remission for years in four patients.

Acknowledgments: The authors thank Drs. J. F. Lifermann and D. M. Chebrou for providing clinical informations and C. Bartoli, F. Boiteau, J. Ferrer, and J. C. Garoste for technical work.

\section{REFERENCES}

1. Robertson LE, Pugh W, O'Brien S, Kantarjian H, HirschGinsberg C, Cork A, et al. Richter's syndrome: a report on 39 patients. J Clin Oncol 1993;11:1985-9.

2. Giles FJ, O’Brien SM, Keating MJ. Chronic lymphocytic leukemia in (Richter's) transformation. Semin Oncol 1998;25: 117-25.

3. Brecher M, Banks PM. Hodgkin's disease variant of Richter's syndrome. Report of eight cases. Am J Clin Pathol 1990;93: 333-9.

4. Rubin D, Hudnall SD, Aisenberg A, Jacobson JO, Harris NL. Richter's transformation of chronic lymphocytic leukemia with Hodgkin's-like cells is associated with Epstein-Barr virus infection. Mod Pathol 1994;7:91-8.

5. Petrella T, Yaziji N, Collin F, Rifle G, Morlevat F, Arnould L, et al. Implication of the Epstein-Barr virus in the progression of chronic lymphocytic leukaemia/small lymphocytic lymphoma to Hodgkin-like lymphomas. Anticancer Res 1997;17: 3907-13.

6. Fayad L, Robertson LE, O’Brien S, Manning JT, Wright S, Hagemeister F, et al. Hodgkin's disease variant of Richter's syndrome: experience at a single institution. Leuk Lymphoma 1996;23:333-7.

7. Simpson JL, Moriarty AT, Earls J, Snyder W, McCloskey DW. Hodgkin's disease variant of Richter's syndrome. Report of a case with diagnosis by fine needle biopsy. Acta Cytol 1997; 41:823-9.

8. Traweek ST, Liu J, Johnson RM, Winberg CD, Rappaport H. High-grade transformation of chronic lymphocytic leukemia and low-grade non-Hodgkin's lymphoma. Genotypic confirmation of clonal identity. Am J Clin Pathol 1993;100:519-26.

9. Foucar K, Rydell RE. Richter's syndrome in chronic lymphocytic leukemia. Cancer 1980;46:118-34.

10. Armitage JO, Dick FR, Corder MP. Diffuse histiocytic lymphoma complicating chronic lymphocytic leukemia. Cancer 1978;41:422-7.

11. Harousseau JL, Flandrin G, Tricot G, Brouet JC, Seligmann M, Bernard J. Malignant lymphoma supervening in chronic lymphocytic leukemia and related disorders. Richter's syndrome: a study of 25 cases. Cancer 1981;48:1302-8.

12. Trump DL, Mann RB, Phelps R, Roberts H, Conley CL. Richter's syndrome: diffuse histiocytic lymphoma in patients with chronic lymphocytic leukemia. A report of five cases and review of the literature. Am J Med 1980;68:539-48.
13. Bernard DJ, Bignon YJ, Pauchard J, Ramos F, Fonck Y, Courjal F, et al. Genotypic analyses of Richter's syndrome. Cancer 1991;67:997-1002.

14. Miyamura K, Osada H, Yamauchi T, Itoh M, Kodera Y, Suchi $\mathrm{T}$, et al. Single clonal origin of neoplastic B-cells with different immunoglobulin light chains in a patient with Richter's syndrome. Cancer 1990;66:140-4.

15. Schots R, Dehou MF, Jochmans K, Heirman C, de Waele M, van Camp B, et al. Southern blot analysis in a case of Richter's syndrome. Evidence for a postrearrangement heavy chain gene deletion associated with the altered phenotype. Am J Clin Pathol 1991;95:571-7.

16. Cofrancesco E, Baldini L, Ciani A, Neri A, Masini T, Chinaglia $\mathrm{D}$, et al. Evidence of clonal progression in a case of Richter syndrome. Cancer 1993;71:741-4.

17. Cherepakhin V, Baird SM, Meisenholder GW, Kipps TJ. Common clonal origin of chronic lymphocytic leukemia and high-grade lymphoma of Richter's syndrome. Blood 1993;82: 3141-7.

18. Koduru PR, Lichtman SM, Smilari TF, Sun T, Goh JC, Karp L, et al. Serial phenotypic, cytogenetic and molecular genetic studies in Richter's syndrome: demonstration of lymphoma development from the chronic lymphocytic leukaemia cells. Br J Haematol 1993;85:613-6.

19. Matolcsy A, Inghirami G, Knowles DM. Molecular genetic demonstration of the diverse evolution of Richter's syndrome (chronic lymphocytic leukemia and subsequent large cell lymphoma). Blood 1994;83:1363-72.

20. Nakamine H, Masih AS, Sanger WG, Wickert RS, Mitchell DW, Armitage JO, et al. Richter's syndrome with different immunoglobulin light chain types. Molecular and cytogenetic features indicate a common clonal origin. Am J Clin Pathol 1992;97:656-63.

21. Brousse N, Solal-Celigny P, Herrera A, Breil P, Molas G, Flejou JF, et al. Gastrointestinal Richter's syndrome. Hum Pathol 1985;16:854-7.

22. Kerim S, Geuna M, Francia di Celle P, Carbone A, Ponti R, Novero D, et al. Heterogeneous immunoglobulin gene rearrangement in a B-chronic lymphocytic leukemia progressing into non-Hodgkin lymphoma (Richter syndrome). Cancer 1993;71:359-63.

23. Ott MM, Ott G, Roblick U, Linke B, Kneba M, de Leon F, et al. Localized gastric non-Hodgkin's lymphoma of high-grade malignancy in patients with pre-existing chronic lymphocytic leukemia or immunocytoma. Leukemia 1995;9:609-14.

24. Sun T, Susin M, Desner M, Pergolizzi R, Cuomo J, Koduru P. The clonal origin of two cell populations in Richter's syndrome. Hum Pathol 1990;21:722-8.

25. Tohda S, Morio T, Suzuki T, Nagata K, Kamiyama T, Imai Y, et al. Richter syndrome with two B cell clones possessing different surface immunoglobulins and immunoglobulin gene rearrangements. Am J Hematol 1990;35:32-6.

26. Chubachi A, Ohtani H, Sakuyama M, Nimura T, Mamiya S, Saitoh M, et al. Diffuse large cell lymphoma occurring in a patient with Waldenstrom's macroglobulinemia. Evidence for the two different clones in Richter's syndrome. Cancer 1991;68:781-5.

27. Scallion R, Wei JP. Upper gastrointestinal hemorrhage from a Mallory-Weiss tear associated with an occult Richter's hernia and small bowel obstruction: to see the forest as well as the trees in the emergency department. J Emerg Med 1994;12:463-6.

28. Givler RL. Lymphocytic leukemia with coexistent localized reticulum cell sarcoma. Cancer 1968;21:1184-92.

29. Jasani B, Gough J, Myers K, Wells AL. Gastrointestinal Richter's syndrome [letter]. Hum Pathol 1986;17:1184.

30. Desablens B, Gineston JL, Joly JP, Piprot-Choffat C, Sevestre $\mathrm{H}$, Capron JP. Immunoblastic lymphoma of the ileocecal region in chronic lymphoid leukemia. Richter's syndrome 
localized in the intestine and disclosed by ascites. Gastroenterol Clin Biol 1987;11:901-3.

31. MacGrogan G, Jollet I, Huet S, Sierankowski G, Picot V, Bonichon F, et al. Comparison of quantitative and semiquantitative methods of assessing MIB-1 with the S-phase fraction in breast carcinoma. Mod Pathol 1997; 10:769-76.

32. Dubus P, Vergier B, Beylot-Barry M, Delaunay MM, Goussot JF, Beylot C, et al. Contribution of histopathologic and molecular analyses to the diagnosis of cutaneous B-cell infiltrates. Mod Pathol 1996;9:1147-55.

33. Altschul SF, Gish W, Miller W, Myers EW, Lipman DJ. Basic local alignment search tool. J Mol Biol 1990;215:40310.

34. Flanagan JD, Rabbitts TH. The sequence of an immunoglobulin epsilon heavy chain constant region gene and evidence for three non-allelic genes. EMBO J 1982;1:655-60.

35. Ohno T, Smir BN, Weisenburger DD, Gascoyne RD, Hinrichs SD, Chan WC. Origin of the Hodgkin/Reed-Sternberg cells in chronic lymphocytic leukemia with “Hodgkin's transformation”. Blood 1998;91:1757-61.
36. Faigel DO, Vaughn DJ, Furth EE, Metz DC. Chronic lymphocytic leukemia: an unusual cause of upper gastrointestinal hemorrhage. Am J Gastroenterol 1995;90:635-7.

37. Chan JK, Ng CS, Isaacson PG. Relationship between highgrade lymphoma and low-grade B-cell mucosa- associated lymphoid tissue lymphoma (MALToma) of the stomach. Am J Pathol 1990;136:1153-64.

38. Hsi ED, Eisbruch A, Greenson JK, Singleton TP, Ross CW, Schnitzer B. Classification of primary gastric lymphomas according to histologic features. Am J Surg Pathol 1998;22: 17-27.

39. Nakamura N, Kuze T, Hashimoto Y, Wakasa H, Kambayashi $\mathrm{H}$, Tanaka T, et al. Richter transformation of a T cell phenotype with p53 gene mutation. Eur J Haematol 1997;59:331-2.

40. Catovsky D. The search for genetic clues in chronic lymphocytic leukemia. Hematol Cell Ther 1997;39:S5-11.

41. Gaidano G, Pastore C, Capello D, Cilli V, Saglio G. Molecular pathways in low grade B-cell lymphoma. Leuk Lymphoma 1997;26:107-13.

42. Ansell SM, Li CY, Lloyd RV, Phyliky RL. Epstein-Barr virus infection in Richter's transformation. Am J Hematol 1999;60: 99-104. 